\title{
Evaluation of shelf-life of fresh-cut pineapple using FT-NIR and FT-IR spectroscopy
}

\author{
Valentina Di Egidio ${ }^{a}$, Nicoletta Sinelli $^{a}$, Sara Limbo $^{a}$, Luisa Torri ${ }^{b}$, \\ Laura Franzetti ${ }^{a}$, Ernestina Casiraghi ${ }^{\mathrm{a}, *}$ \\ a Department of Food Science and Microbiology, Università degli Studi di Milano, Via Celoria 2, 20133 Milan, Italy \\ ${ }^{\mathrm{b}}$ University of Gastronomic Sciences, Piazza Vittorio Emanuele 9, 12060 Bra (CN), Italy
}

\section{A R T I C L E I N F O}

\section{Article history:}

Received 30 March 2009

Accepted 20 June 2009

\section{Keywords:}

Fresh cut fruit

Pineapple

Shelf-life

NIR spectroscopy

MIR spectroscopy

\begin{abstract}
A B S T R A C T
The aim of this work was to investigate the loss of freshness of fresh-cut pineapple samples stored at different temperatures using non-destructive spectroscopic methods. Three lots of fresh cut pineapples (Ananas comosus L. cv. Golden Ripe, from Costa Rica), packaged in PVC trays $(250 \mathrm{~g})$ were analyzed during storage at three different temperatures $\left(5.3,8.6\right.$ and $15.8^{\circ} \mathrm{C}$ ). Loss of quality of these fruit was evaluated by chemical and microbiological parameters and using NIR and MIR spectroscopy. The FT-NIR spectra were acquired in reflectance mode directly on the slice of fresh-cut pineapple, over the range $12,500-3900 \mathrm{~cm}^{-1}$, while FT-IR spectra were collected over the range $4000-700 \mathrm{~cm}^{-1}$ using an horizontal ATR cell. Some chemical and microbiological parameters were also measured. Principal component analysis (PCA) was applied to the second derivative of the spectra to uncover molecular modifications occurring over the storage time. A clear discrimination between "fresh" and "old" samples was obtained and a stability time corresponding to the time of the initial loss of freshness was defined at each temperature. The stability times revealed by NIR spectroscopy were in good accordance with those evaluated by MIR. At each temperature the stability times (i.e. the initial loss of freshness times) defined by spectroscopic techniques $\left(4-5 \mathrm{~d}\right.$ at $5.3^{\circ} \mathrm{C}, 3-4 \mathrm{~d}$ at $8.6^{\circ} \mathrm{C}$ and $1 \mathrm{~d}$ at $15.8^{\circ} \mathrm{C}$ ) were associated with a mesophilic bacteria count ranging between $10^{5}$ and $10^{6}$ $\mathrm{CFU} \mathrm{g}^{-1}$ and lower than the maximum limit for mesophilic bacteria $\left(<5 \times 10^{7} \mathrm{CFU} \mathrm{g}^{-1}\right)$ given by French hygienic regulations at consumption.

These results show that NIR and MIR spectroscopy could support conventional techniques (chemical and microbiological analysis) in studying shelf-life of fresh-cut fruit. In particular these techniques define the initial loss of freshness time, indicating a product which rapidly will be no longer acceptable if stored beyond that time. The main advantage of using IR spectroscopic techniques is to rapidly draw a profile of the product related to its change in quality.
\end{abstract}

(c) 2009 Elsevier B.V. All rights reserved.

\section{Introduction}

Market sales of ready-to-use fresh fruit have grown rapidly in the recent years as a result of changes in consumer attitudes. The international Fresh-cut Produce Association (IFPA) defines freshcut products as "any fruit or vegetable or combination thereof that has been physically altered from its original form, but remains in a fresh state". Quality of fresh-cut fruit products determines their value to consumers and is a combination of attributes, properties or characteristics including appearance, texture, flavour and nutritional value.

Because the tissue integrity of these products has been altered during processing, fresh-cut fruit are more perishable than the orig-

\footnotetext{
* Corresponding author. Tel.: +39 02 50319184; fax: +39 0250319190.

E-mail address: ernestina.casiraghi@unimi.it (E. Casiraghi).
}

inal raw materials (Shewfelt, 1994). Fresh-cut processing causes wounding, increases metabolic activities and delocalization of enzymes and substrates. This may lead to deterioration such as browning, softening, decay and off-flavour development. These manipulations result also in increased rates of respiration and ethylene production and may reduce the shelf-life of fresh-cut fruit commodities (Varoquaux and Wiley, 1997). On the whole fresh-cut products have a short shelf-life, up to some days, because they have to preserve sensory and nutritional characteristics of fresh products and pathogenic microbial species must not develop (Shah and Nath, 2006).

Several studies have been carried out to monitor the shelf-life of fresh-cut fruit and vegetables by using chemical, physical and microbiological indices. In addition predictive models are useful tools both to understand degradation phenomena during shelflife and to optimise storage conditions, especially when kinetic phenomena are modelled under dynamically varying conditions 
(Corbo et al., 2006). Mathematical models to predict microbial stability, chemical and sensory quality of different fresh-cut vegetables and fruit have been studied by several authors (Riva et al., 2001; Lauridsen and Knøchell, 2003; Rocha and Morais, 2003; Lavelli et al., 2006; Zanoni et al., 2007; Montero-Calderon et al., 2008).

Even if traditional methods have been successfully used for studying shelf-life of fresh-cut fruit and vegetables, they are expensive, slow, require considerable analytical skill and are not suited to automation. Rapid and non-destructive methods to investigate the loss of freshness of the food product have recently increased in importance. Infrared spectroscopy in both the near (NIR) and mid (MIR) regions appears to be one of the most powerful and convenient analytical tools which can be used for studying the shelf-life of food, given that absorption in these spectral ranges can be related, to a greater or lesser degree, to the main chemical components of foods, such as proteins, carbohydrates, fats and waters. In particular, in the NIR region (between 750 and $2500 \mathrm{~nm}$ ), vibration and combination overtones of the fundamental $\mathrm{O}-\mathrm{H}, \mathrm{C}-\mathrm{H}$ and $\mathrm{N}-\mathrm{H}$ bounds are the main recordable phenomena (Williams and Norris, 2001), while the MIR measurements provide information on fundamental frequencies of chemical bonds in functional groups such as $\mathrm{C}-\mathrm{C}$, $\mathrm{C}-\mathrm{H}, \mathrm{O}-\mathrm{H}, \mathrm{C}=\mathrm{O}$ and N-H (Colthup et al., 1990; Coates, 2000).

In recent years, NIR and MIR spectroscopy has become a valid tool supporting chemical methods. Several studies have been reported on the use of NIR and MIR spectroscopy as a rapid and cost-effective analytical tool to determine the food structure and properties in fundamental research and as on-line sensors for monitoring process (Ozaki et al., 2006; Nicolaï et al., 2007). Nevertheless, only few studies have addressed the application of NIR and MIR spectroscopy in shelf-life studies; Cattaneo et al. (2005) used NIR and MIR spectroscopy to study shelf-life of Crescenza cheese stored at different temperatures, while Sinelli et al. (2005) applied NIR spectroscopy to monitor the shelf-life of packed industrial ricotta cheese.

The aim of this work was to monitor, using Fourier transform (FT)-NIR and (FT)-IR spectroscopy, the main changes occurring during the commercial life of fresh-cut pineapple stored at different temperatures. In conjunction with this, microbiological and chemical changes were monitored with traditional analytical methods in order to evaluate the feasibility of FT-NIR and FT-IR spectroscopy as a rapid non-invasive approach for monitoring the shelf-life of fresh-cut fruit.

\section{Materials and methods}

\subsection{Samples}

Three lots of fresh-cut pineapple (Ananas comosus L. cv. Golden Ripe, from Costa Rica), packaged in PVC trays (250 g), supplied by the manufacturer at the beginning of their commercial life, were analyzed during storage at three different temperatures (4, 8 and $\left.16^{\circ} \mathrm{C}\right)$. Storage temperature was continuously monitored using small time-temperature recording devices (TB Econorma S.a.s, Treviso, Italy; water proof, $\pm 0.5^{\circ} \mathrm{C}$ temperature precision, diameter $=10 \mathrm{~mm}$, thickness $=4 \mathrm{~mm}$ ). Three samples were monitored for each temperature, resulting in average temperatures during storage of $5.3,8.6$ and $15.8^{\circ} \mathrm{C}$, with a standard deviation of replicates of about $0.5^{\circ} \mathrm{C}$.

Samples stored at 5.3 and $8.6^{\circ} \mathrm{C}$ were analyzed every day over a ten day period, and those stored at $15.8^{\circ} \mathrm{C}$ over six days. For each sampling, three trays were used to carry out chemical and microbial analysis, FT-NIR and FT-IR spectroscopy.

\subsection{Chemical methods}

At each sampling, fresh-cut pineapple was analyzed for total soluble solids content, titratable acidity and $\mathrm{pH}$. Fresh-cut fruit pieces
(50 g) were homogenized using an Ultra Turrax T25 (IKA WERKE, Germany) and filtered (Whatman paper no. 1). Total soluble solids content was determined on filtered juice using a hand refractometer (Atago mod. N1, Tokyo, Japan) and expressed as percent. Filtered pulp (10-15 g) was titrated with $0.1 \mathrm{~N}$ of $\mathrm{NaOH}$ to $\mathrm{pH} 8.1$, using an automatic sample titrator (Crison, Titromatic 2S-3B, USA). Titratable acidity was expressed as grams of anhydrous citric acid in $100 \mathrm{~g}$ of fruit (fresh weight). Soluble solids content and acidity results are the average of two determinations. $\mathrm{pH}$ was directly measured on pineapple slices using a pH meter (XS Instruments 510, Opto-Lab, Italia). Nine measurements, three readings from each of three slices, were carried out for each sampling.

\subsection{Microbial analysis}

The samples ( $10 \mathrm{~g}$ of pineapple) were aseptically removed from each package, transferred into a sterile bag, diluted with $90 \mathrm{~mL}$ of $0.85 \%$ sterile tryptone salt solution and homogenized for $30 \mathrm{~s}$ at $230 \mathrm{rpm}$ in a stomacher (Seeword 400 Circulator, England). Decimal progressive dilutions were prepared and the following microbial determinations were performed: mesophilic aerobic bacteria count or total bacteria count (TBC) by pouring plates in Plate Count Agar (PCA) (Merck, USA) and incubation at $30 \pm 1^{\circ} \mathrm{C}$ for $48-72 \mathrm{~h}$ (ISO 4833:2003); yeast and mould spread plates in Yeast Glucose Chloramphenicol Agar (YCG) (Merck, USA) and incubation at $25^{\circ} \mathrm{C}$ for 2-5 $\mathrm{d}$. All the microbiological determinations were carried out in triplicate and the results were expressed as the average colony forming units per grams $\left(\mathrm{CFU} \mathrm{g}^{-1}\right)$.

\subsection{FT-NIR spectroscopy}

The analysis was performed by using a FT-NIR spectrometer (MPA, Bruker Optics, Ettlingen, Germany) equipped with an integrative sphere. The spectra were acquired in reflectance mode directly on the pineapple slice, over the range $12,500-3900 \mathrm{~cm}^{-1}$ (resolution: $32 \mathrm{~cm}^{-1}$; scanner velocity: $10 \mathrm{kHz}$; background: 128 scans, sample: 128 scans). OPUS software (v. 6.5 Bruker Optics, Ettlingen, Germany) was used for spectral acquisition and instrumental control. For each sampling, seven pieces of pineapple were analyzed at room temperature and the average spectra were used for further evaluations.

\subsection{FT-IR spectroscopy}

FT-IR measurements were taken using a spectrometer (VERTEX 70, Bruker Optics, Ettlingen, Germany) equipped with a deuterated triglycine sulfate (DTGS) detector. Spectra were recorded using an in-compartment benchmark attenuated total reflectance (ATR) through a top plate by use of a $45^{\circ}$ germanium crystal with 11 internal reflections (Pike Technologies, Inc., Madison, USA). For both background and sample readings, 32 scans were co-added at a nominal resolution of $8 \mathrm{~cm}^{-1}$; single beam spectra of the samples were collected and ratioed against a background of air. Fresh-cut pineapple slices were squeezed and pressed on the ATR plate, in order to cover the crystal with juice. For each sample, spectral data were collected in the range $4000-700 \mathrm{~cm}^{-1}$ at room temperature $\left(20 \pm 0.5^{\circ} \mathrm{C}\right)$. OPUS software (v. 6.5, Bruker Optics, Ettlingen, Germany) was used for spectral acquisition, instrument control and preliminary file manipulation.

\subsection{NIR and MIR data processing}

Both NIR and MIR spectra were analyzed by using The Unscrambler (v 9.7, Camo, Inondhcim, Norway) software. In order to minimize the effect of baseline shifts, the spectral data were preprocessed by several mathematical treatments. The best pre-treatment 
Table 1

Average values and relative standard deviation for total soluble solids content, titratable acidity and pH during storage.

\begin{tabular}{|c|c|c|c|c|c|c|}
\hline \multirow[t]{2}{*}{ Temperature $\left({ }^{\circ} \mathrm{C}\right)$} & \multicolumn{2}{|c|}{ Total soluble solid (\%) } & \multicolumn{2}{|c|}{ 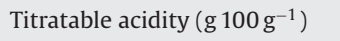 } & \multicolumn{2}{|l|}{$\mathrm{pH}$} \\
\hline & Average & SD & Media & SD & Media & SD \\
\hline 5.3 & 11.9 & 0.24 & 0.71 & 0.08 & 3.61 & 0.12 \\
\hline 8.6 & 10.5 & 0.08 & 0.80 & 0.12 & 3.54 & 0.09 \\
\hline 15.8 & 11.9 & 0.17 & 0.75 & 0.11 & 3.59 & 0.13 \\
\hline
\end{tabular}

useful to give the most important information was the second derivative transformation (Savitzky-Golay method, gap size $=15$ data points). Principal component analysis (PCA) was applied, as an exploratory tool, to spectral data to uncover molecular modifications during storage. PCA identifies orthogonal directions of maximum variance in the original dataset in decreasing order and projects the data onto a lower-dimensionality space formed by a subset of the highest-variance components. The orthogonal directions are linear combinations of the original variables and each component explains in turn a part of the total variance of the data; in particular, the first significant component explains the largest percentage of the total variance, the second one, the second largest percentage, and so forth (Beebe et al., 1998; Naes et al., 2000). All spectral data sets were mean-centered before performing PCA calculations. For NIR and MIR data, PCA was performed over the range $11.000-3.950 \mathrm{~cm}^{-1}$ and $1800-870 \mathrm{~cm}^{-1}$, respectively.

The values of the PC scores obtained by PCA applied to the all samples stored at three temperatures $\left(5.3,8.6\right.$ and $\left.15.8^{\circ} \mathrm{C}\right)$ were modelled for each temperature as a function of time during storage to identify the stability times, i.e. the time of initial freshness decay (Table Curve Software, v. 4.0, Jandel Scientific, San Rafael, CA, USA). The second derivative maximum value was calculated on the curve models and corresponded to the maximum acceleration of shelf-life process.

\section{Results and discussion}

Soluble solids content (SS), titratable acidity (TA) and $\mathrm{pH}$ showed little change during storage. Average values and the relative standard deviation for these parameters, measured during storage at each temperatures, are shown in Table 1. Similar trends for these parameters were found by Gil et al. (2006) and Montero-Calderon et al. (2008). Data variability reported in these studies could be associated with the type of cultivar and the maturity stages of the fruit.

The microbial growth on fresh-cut pineapple during storage at each temperature is shown in Fig. 1, and at each temperature shows a different trend. Also, the starting levels of microbial population were different, since the samples stored at the three temperatures belonged to three different lots.

The initial value ranged from 3 to $4 \log \mathrm{CFU} \mathrm{g}^{-1}$ for mesophilic bacteria and reached about $7 \log \mathrm{CFU} \mathrm{g}^{-1}$ after $8-10 \mathrm{~d}$ of storage at $5.3^{\circ} \mathrm{C}$, after $4-5 \mathrm{~d}$ at $8.6^{\circ} \mathrm{C}$ and after about $2 \mathrm{~d}$ of storage at $15.8^{\circ} \mathrm{C}$ (Fig. 1a). Similar increases were observed for yeasts at each temperature (Fig. 1b). As expected, the growth towards the final values of $7 \log \mathrm{CFU} \mathrm{g}^{-1}$ was more rapid at the highest temperatures for mesophilic bacteria and yeasts. Similar values for mesophilic bacteria, moulds and yeast were obtained by Montero-Calderon et al. (2008), who found 7-7.5 $\log \mathrm{CFU} \mathrm{g}^{-1}$ of moulds and yeasts and $7 \log$ CFU g $^{-1}$ of mesophilic bacteria in fresh-cut 'Gold' pineapple packaged in different conditions and stored at $5{ }^{\circ} \mathrm{C}$ for $18 \mathrm{~d}$.

The raw results of the spectroscopic data are shown in Fig. 2, including FT-NIR (a) and FT-IR (b) raw spectra of fresh-cut pineapple collected during storage. Both the near and the mid infrared spectra of all samples were quite homogeneous and did not show obvious differences and no outliers were identified a priori by visual inspection. In the FT-NIR spectra (Fig. 2a) the absorption bands at 10,244 and $6996 \mathrm{~cm}^{-1}$ are related to the second $-\mathrm{O}-\mathrm{H}$ overtone and to the first $-\mathrm{O}-\mathrm{H}$ overtone of water, respectively. The peaks at 8454 and $5623 \mathrm{~cm}^{-1}$ are associated with the absorption band of the second overtone and the first overtone of $-\mathrm{C}-\mathrm{H}$ stretch, respectively. The absorbance at $5237 \mathrm{~cm}^{-1}$ is attributed to the $-\mathrm{O}-\mathrm{H}$ combination band of water (Williams and Norris, 2001). The FT-IR spectra of pineapple (Fig. 2b) collected during storage are dominated by peaks attributed mostly to water $\left(3356 \mathrm{~cm}^{-1}-\mathrm{O}-\mathrm{H}\right.$ stretching and $1635 \mathrm{~cm}^{-1}-\mathrm{O}-\mathrm{H}$ bending) and to sugars and organic acids, in the range $1120-995 \mathrm{~cm}^{-1}$ (coupled C-O and C-C stretching vibration) (Coates, 2000; Workman, 2001). After a second derivative treatment, several spectral features became more apparent. In the NIR region, absorbance at $7274-7143$ and $5408-5276 \mathrm{~cm}^{-1}$ has been attributed to water, while the absorbance at 5931-5631 and $4500 \mathrm{~cm}^{-1}$ are related to the first overtone -C-H stretch and combination band -C-H stretch of sugar and organic acids, respectively (Williams and Norris, 2001). MIR spectra are dominated by some peaks attributed to $-\mathrm{O}-\mathrm{H}$ stretch $\left(3691,3394,3232 \mathrm{~cm}^{-1}\right)$ and $\mathrm{OH}$ bending $\left(1643,1581 \mathrm{~cm}^{-1}\right)$ of water.

The absorption bands attributed to sugars and organic acids are more evident in the second derivative plot, which are dominated by peaks at 1500,1434,1380,1290, 1180, 1141, 1107, 1056, 956 and $879 \mathrm{~cm}^{-1}$. In particular, bands appearing between 1500 and $1290 \mathrm{~cm}^{-1}$ are associated with $\mathrm{C}-\mathrm{H}_{2}$ and $\mathrm{C}-\mathrm{H}_{3}$ deformation bands
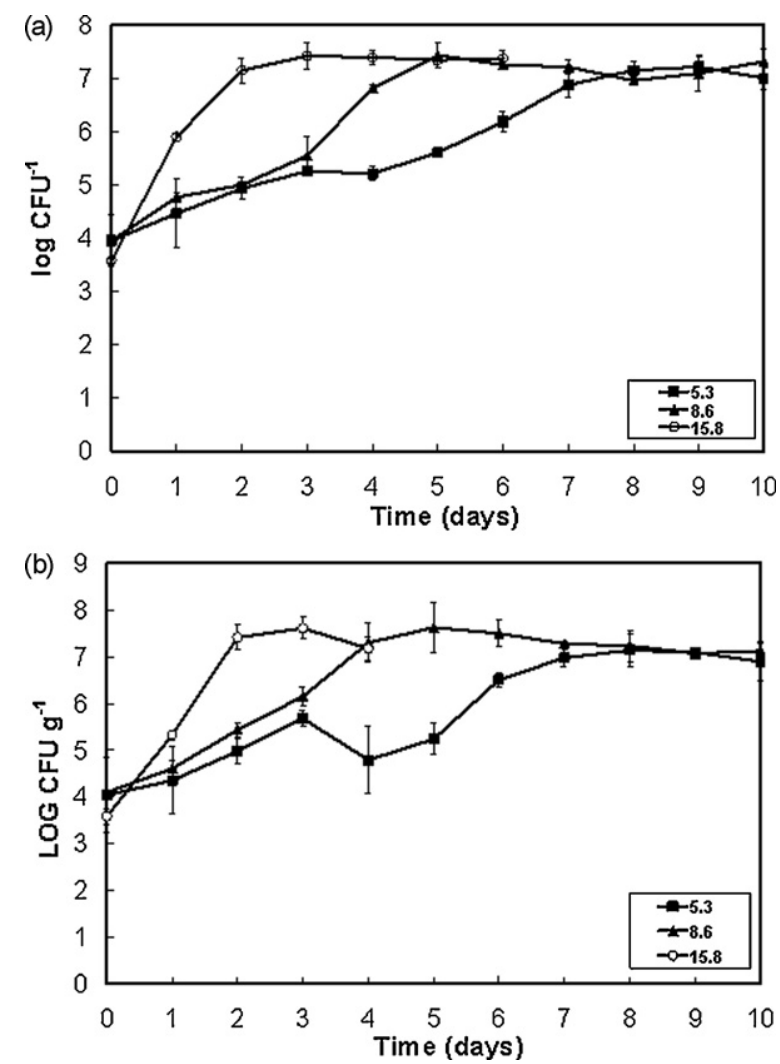

Fig. 1. Changes in mesophilic bacteria (a) and yeast (b) on fresh-cut pineapple during storage at each temperature. 

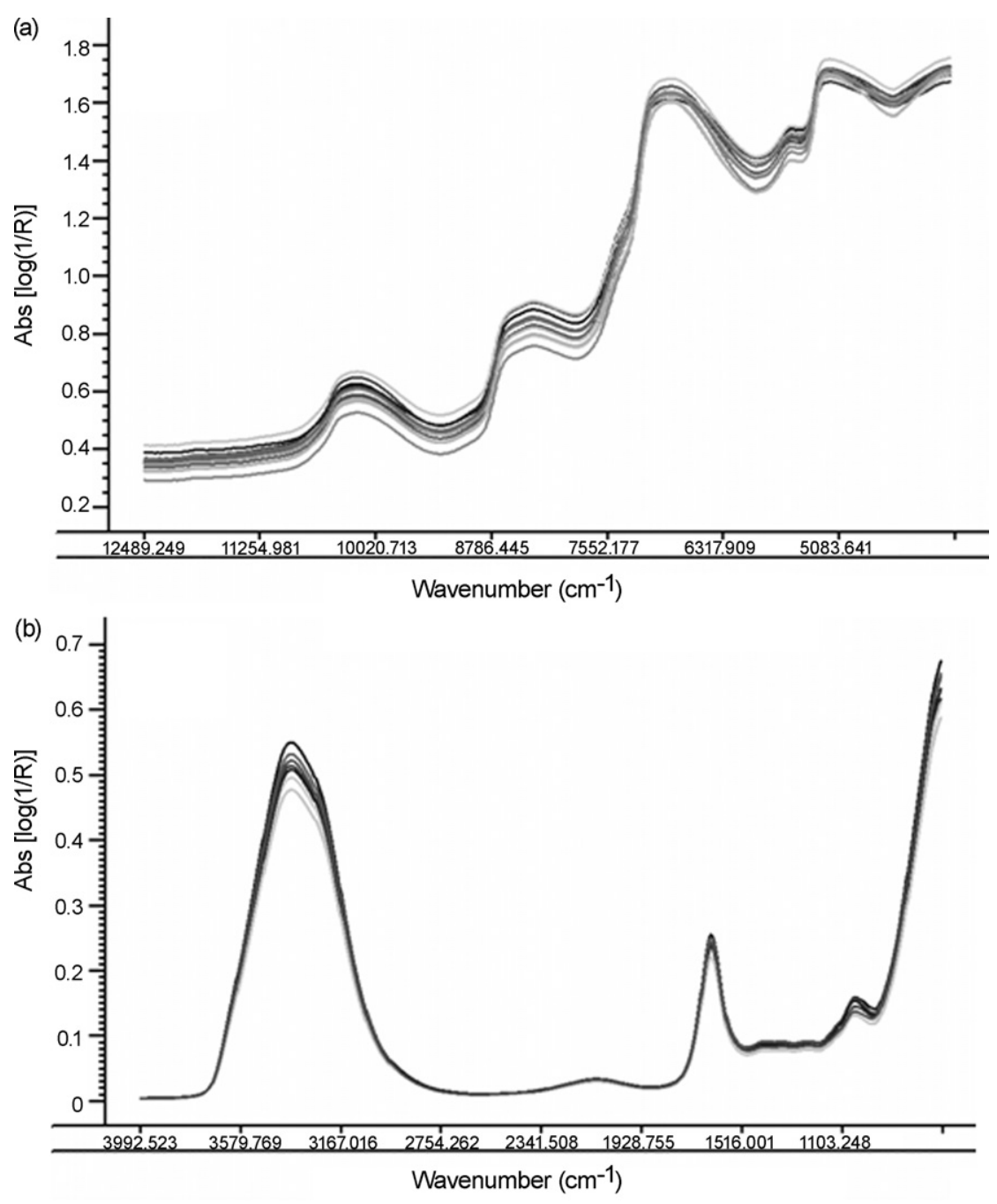

Fig. 2. FT-NIR (a) and FT-IR (b) raw spectra of fresh-cut pineapple during storage.

of sugars and organic acids, while the peaks in the region between 1180 and $1056 \mathrm{~cm}^{-1}$ arise mainly from $\mathrm{C}-\mathrm{O}$ and $\mathrm{C}-\mathrm{C}$ of sugars and organic acids (Coates, 2000; Workman, 2001).

Both for NIR and MIR spectra, PCA were performed on the second derivative spectra, and the sample scores calculated on PCs 1 and 2 were plotted, together with the loading plots of the first two principal components in order to uncover molecular modifications during storage.

Examining the score plot, obtained by applying PCA to NIR spectra over the range $11.000-3.950 \mathrm{~cm}^{-1}$, in the area defined by the first two principal components, a satisfactory sample distribution was found according to the storage conditions (Fig. 3a). On the score plot, for each temperature, the number beside each point represents for each temperature the storage time in days. In particular, the first two principal components ( $100 \%$ of the total variance) were able to separate, for each storage temperature, the samples in two groups, named "fresh" and "old". In particular, "fresh" samples corresponded to fresh-cut pineapple stored up to $5 \mathrm{~d}, 4 \mathrm{~d}$ and less than 1 d at $5.3^{\circ} \mathrm{C}, 8.6^{\circ} \mathrm{C}$ and $15.8^{\circ} \mathrm{C}$, respectively. Conversely, "old" samples corresponded to samples stored for longer than $6 \mathrm{~d}, 5 \mathrm{~d}$ and $2 \mathrm{~d}$ at $5.3^{\circ} \mathrm{C}, 8.6^{\circ} \mathrm{C}$ and $15.8^{\circ} \mathrm{C}$, respectively. In an attempt to uncover the causes of these score patterns, the loadings of the first two principal components were studied and a number of significant features were identified (Fig. 3b). In particular, 8863 and $5631 \mathrm{~cm}^{-1}$ corresponds to the second and first overtones of $\mathrm{C}-\mathrm{H}$ of sugar, respectively; 7251-7127 and 5415-5284 $\mathrm{cm}^{-1}$ corresponds to the first overtone and $\mathrm{O}-\mathrm{H}$ bending and asymmetric stretching combination band of water and $4512 \mathrm{~cm}^{-1}$ corresponds to the combination band of the $\mathrm{C}-\mathrm{H}$.

In order to define a stability time, corresponding to the time of an initial freshness decay, the PC1 scores were plotted against time and modelled using a sigmoid function, expressed as

$y=\frac{a+b}{[1+\exp (c-x) / d]}$

where $a$ is the maximum shift (from initial to equilibrium value) of the considered index (PC1 scores), $b$ is the transition center, $x$ is the storage time, and $c$ and $d$ are two constants. The use of this type of sigmoidal function is justified by the nature (enzymatic or microbial-induced) of the transformation in progress (Benedetti et al., 2005; Sinelli et al., 2008). In Fig. 4 the modelling of these data is shown: the minimum of the second derivative of the empirical transition function, obtained interpolating PC1 scores at each temperature, allows the measurement of the related stability time. The stability time $\left(5 \mathrm{~d}\right.$ at $5.3^{\circ} \mathrm{C} ; 3.4 \mathrm{~d}$ at $8.6^{\circ} \mathrm{C}$ and $1.1 \mathrm{~d}$ at $15.8^{\circ} \mathrm{C}$ ) was for each storage condition the time after which the product will be no longer acceptable as revealed by NIR spectroscopy.

The same multivariate approach was used to analyze the FT-IR spectra collected during storage (Fig. 5). The PCs score plot (Fig. 5a) showed that it was possible to obtain a good sample distribution along the PC1 axis according to the increase of storage time. As for NIR spectroscopy the first two principal components (91\% of 

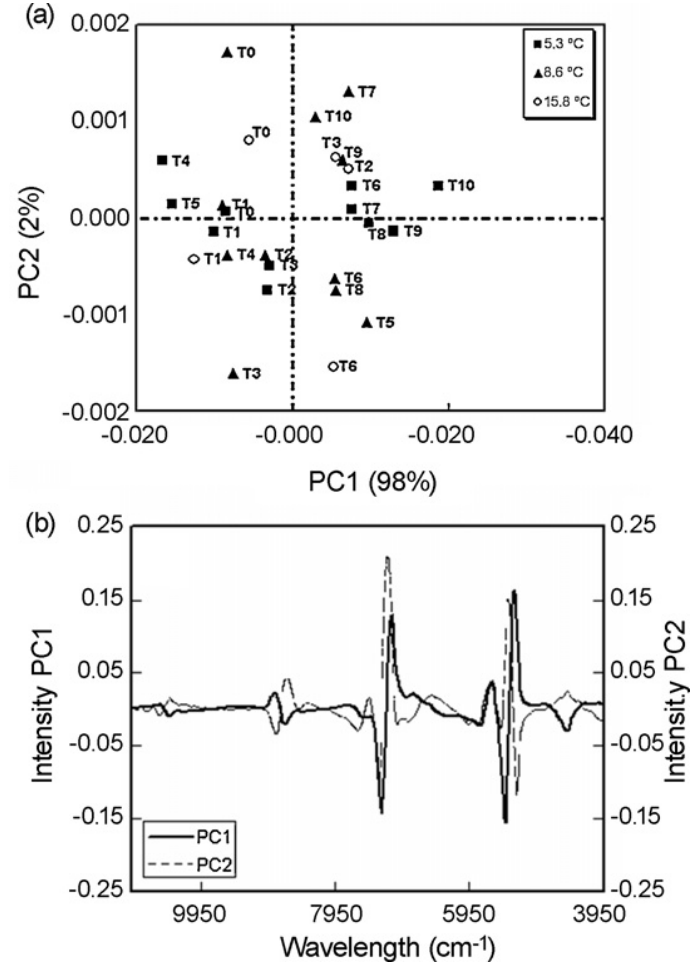

Fig. 3. Principal component scores (a) and line plots (b) on PC1 and PC2 of FT-NIR second derivative spectra of fresh-cut pineapple during storage.

the total variance) were able to separate the samples in two groups ("fresh" and "old"), at each storage temperature. The samples stored up to $5 \mathrm{~d}$ at $5.3^{\circ} \mathrm{C}$, up to $3 \mathrm{~d}$ at $8.6^{\circ} \mathrm{C}$ and $1 \mathrm{~d}$ at $15.8^{\circ} \mathrm{C}$ were considered "fresh", while all samples stored for longer times resulted "old". Loadings of principal components 1 and 2 (Fig. 5b) were characterized by contributions from water $\left(1639-1500 \mathrm{~cm}^{-1}, \mathrm{OH}\right.$ stretching), sugar and organic acid $\left(1500 \mathrm{~cm}^{-1}-\mathrm{C}-\mathrm{H}_{3}\right.$ scissoring vibration, $1184-950 \mathrm{~cm}^{-1}$, C-O stretching vibration).

As was the case for NIR spectra, the PC1 FT-IR scores were plotted against time and the second derivative was calculated, in order to define the stability time, i.e. the initial freshness decay time. The stability times revealed by MIR spectroscopy $\left(4 \mathrm{~d}\right.$ at $5.3^{\circ} \mathrm{C}$; $3.4 \mathrm{~d}$ at $8.6^{\circ} \mathrm{C}$ and $1.1 \mathrm{~d}$ at $15.8^{\circ} \mathrm{C}$ ) were in good accordance with those evaluated by NIR technique. At each temperature the stability times defined by spectroscopic techniques $\left(4-5 \mathrm{~d}\right.$ at $5.3^{\circ} \mathrm{C}$, $3-4 \mathrm{~d}$ at $8.6^{\circ} \mathrm{C}$ and $1 \mathrm{~d}$ at $15.8^{\circ} \mathrm{C}$ ) are associated with the initial freshness decay times. In fact, at these stability times, the samples had a mesophilic bacteria count ranging between $10^{5}$ and $10^{6} \mathrm{CFU} \mathrm{g}^{-1}$ and lower than the maximum limit for mesophilic bacteria $\left(<5 \times 10^{7} \mathrm{CFU} \mathrm{g}^{-1}\right)$ given by the French hygienic regulations at

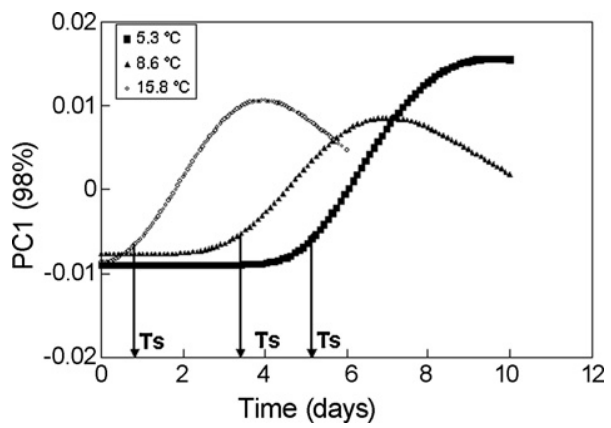

Fig. 4. Modelling of PC1 scores versus time for fresh-cut pineapple samples stored at $5.3,8.6$ and $15.8^{\circ} \mathrm{C}$.

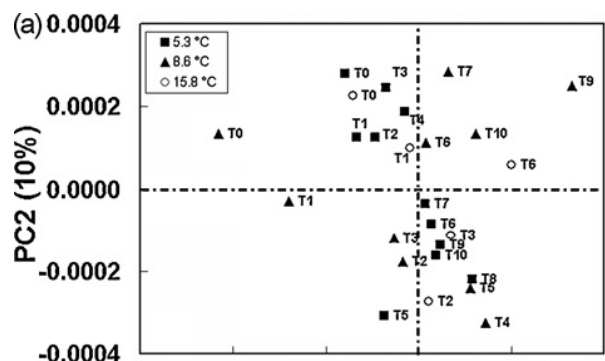

$\begin{array}{llllll}0.0015 & -0.0010 & -0.0005 & 0.0000 & 0.0005 & 0.0010\end{array}$

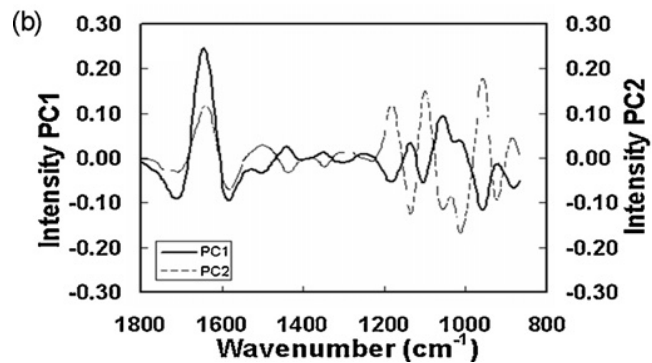

Fig. 5. Principal component scores (a) and line plots (b) on PC1 and PC2 of FT-IR second derivative spectra of fresh-cut pineapple during storage.

consumption (Ministère de l'Economie des Finances et du Budget, 1988).

Therefore we can assess that the spectroscopic methods are able to define, depending on temperature, the initial time for loss of freshness, indicating a product which rapidly will be no longer acceptable if stored beyond that time.

\section{Conclusions}

Results of this study show that non-destructive methods, such as NIR and MIR spectroscopy could support conventional techniques (chemical and microbiological analysis) in studying shelf-life of fresh-cut fruit. The main advantage of using the IR spectroscopic techniques is to rapidly draw a profile of the product related to its quality. In fact, FT-NIR and FT-IR spectroscopy monitor the molecular modification occurring in fresh products during storage and allow the definition of a stability time associated with them. The initial loss of freshness revealed by IR was confirmed by microbial decay, thus strengthening our results and rendering the use of fresh-cut fruit safe. In fact, the main changes occurring in the spectra during storage are associated with water loss and composition modification in the product, which might be also due to microbial development.

The approach used in this study can be applied to evaluate the loss of quality of other fresh-cut products, in which enzymatic and microbiological processes are responsible for freshness loss with a negative influence on the product quality and appearance during storage.

\section{Acknowledgement}

We dedicate this work to the memory of Prof. Marco Riva, a valued colleague and scientist, who has died unexpectedly.

\section{References}

Beebe, K.R., Pell, R.J., Seasholtz, M.B. (Eds.), 1998. Chemometrics, A Practical Guide. John Wiley and Sons, New York.

Benedetti, S., Sinelli, N., Buratti, S., Riva, M., 2005. Shelf life of Cresenza cheese as measured by electronic nose. J. Dairy Sci. 88, 3044-3051.

Cattaneo, T.M.P., Giardina, C., Sinelli, N., Riva, M., Giangiacomo, R., 2005. Application of FT-NIR and FT-IR spectroscopy to study the shelf-life of Crescenza cheese. Inter. Dairy J. 15, 693-700. 
92

V. Di Egidio et al. / Postharvest Biology and Technology 54 (2009) 87-92

Coates, J., 2000. Interpretation of infrared spectra, a practical approach. In: Beyers, R.A. (Ed.), Encyclopaedia of Analytical Chemistry. John Wiley and Sons Ltd., Chichester, pp. 10815-10837.

Colthup, N.B., Duly, L.H., Wiberly, S.E. (Eds.), 1990. Introduction to Infrared and Roman Spectroscopy, third ed. Academic Press, Inc., New York.

Corbo, M.R., Del Mobile, A., Sinigaglia, M., 2006. A novel approach for calculating shelf life of minimally processed vegetables. Int. J. Food Microbiol. 106, 69-73.

Gil, M.A., Aguayo, E., Kader, A.A., 2006. Quality changes and nutrient retention in fresh-cut versus whole fruits during storage. J. Agric. Food Chem. 54, 4284-4296.

International Organization for Standardization (ISO) no. 4833. 2003. Microbiology of Food and Animal Feeding Stuffs: Horizontal Method for the Enumeration of Microorganisms Colony-Count Technique at $30^{\circ} \mathrm{C}$.

Lauridsen, L., Knøchell, S., 2003. Microbiological stability and diversity in raw porepeeled potatoes packed in different atmospheres. Eur. Food Res. Technol. 217, 421-426.

Lavelli, V., Pagliarini, E., Ambrosoli, R., Minati, J.L., Zanoni, B., 2006. Physicochemical, microbial, and sensory parameters as indices to evaluate the quality of minimally-processed carrots. Postharvest Biol. Technol. 40, 34-40.

Ministère de l'Economie dens Finances et du Budget, 1988. Marché consommation, produits vegetaux prêts à l'emploi dits de la "IVemme gamme": guide de bonne pratique hygiéniques. J. Off. République Française 1621:1-29.

Montero-Calderon, M., Rojas-Graü, M.A., Martin-Belloso, O., 2008. Effect of packaging conditions on quality and shelf-life of fresh-cut pineapple (Ananias comosus). Postharvest Biol. Technol. 50, 182-189.

Noes, T., Isaksson, T., Fearn, T., Davies, A.M.C. (Eds.), 2000. A User-friendly Guide to Multivariate Calibration and Classification. NIR Publications, Chichester, UK.

Nicolaï, B.M., Beullens, K., Bobelyn, E., Peers, A., Saeys, W., Theron, K.I., Lammertyn, J., 2007. Nondestructive measurement of fruit and vegetables quality by means of NIR spectroscopy: a review. Postharvest Biol. Technol. 46, 99-108.
Ozaki, Y., McClure, W.F., Christy, A.A.(Eds.), 2006. Near-infrared Spectroscopy in Food Science and Technology. Wiley and Sons, Inc., Publication.

Kiva, M., Franzetti, L., Galli, M., 2001. Microbiological quality and shelf-life modeling of ready-to-eat cicorino. J. Food Protec. 64, 228-234.

Rocha, A.M.C.N., Morris, A.M.M.B., 2003. Shelf life of minimally processed apple (cv. Jonagored) determined by colour changes. Food Control 14, 13-20.

Shah, N.S., Neath, N., 2006. Minimally processed fruits and vegetables-freshness with convenience. J. Food Sci. Technol. 43, 561-570.

Shewfelt, R., 1994. Quality characteristics of fruits and vegetables. In: Singh, R.P., Oliveira, F.A.R. (Eds.), Minimal Processing of Foods and Process Optimization: An Interface. CRC Press, Bock Ration, FL, pp. 171-189.

Sinelli, N., Barzaghi, S., Giardina, C., Cattaneo, T.M.P., 2005. A preliminary study using Fourier transform near infrared spectroscopy to monitor the shelf-life of packed industrial ricotta cheese. J. Near Infrared Spectrosc. 13, 293-300.

Sinelli, N., Casiraghi, E., Downey, G., 2008. Studies on proving of yeasted bread dough using near and mid-infrared spectroscopy. J Agric Food Chem. 56, 922-931.

Varoquaux, P., Wiley, R.C., 1997. Biological and biochemical changes in minimally processed refrigerated fruits and vegetables. In: Wiley, R.C. (Ed.), Minimally Procensed Refrigerated Fruits and Vegetables. Chapman and Hall, New York, pp. 226-268.

Williams, P., Norris, K., 2001. Near Infrared Technology in the Agricultural and Food Industries, second ed. American Association of Cereal Chemist, St. Paul, MN, USA.

Workman, J., 2001. Review of interpretive spectroscopy for Roman and infrared. In: Workman, J. (Ed.), Handbook of Organic Compounds. Academic Press, London, pp. 209-242.

Zanoni, B., Lavelli, V., Ambrosoli, R., Garavaglia, L., Minati, J., Paglierini, E., 2007. A model to predict shelf-life in air and darkness of cut, ready-to-use, fresh carrots under both isothermal conditions. J. Food Eng. 79, 586-591. 